\title{
THE USE OF AIR HANDLING UNITS IN RESIDENTIAL NEAR ZERO-ENERGY BUILDINGS
}

\author{
EMMI GIUSEPPE, MARIOTTI MARCO, ZARELLA ANGELO, DE CARLI MICHELE \\ Department of Industrial Engineering, DII, University of Padova, Italy
}

\begin{abstract}
The present work focuses on the advantages of using air-handling units in residential buildings characterized by high thermal insulation level. This type of buildings is the so-called "nearly zero energy buildings" because of low energy consumption for heating and cooling. Differently to what usually happened in the past, where the main costs of the air conditioning were related the heating purpose, today the main problem in mild climate condition is the cooling of the building, due to the high thermal resistance of the structures which does not allow the exchange of heat with the external ambient in summer especially during the night. The nowadays mechanical ventilation systems, however are equipped with a bypass of the heat recovery unit; this solution anyway does not seem adequate to be used for free-cooling operation. On the other hand, the use of radiant panels emission systems, very diffused in the last years, make difficult to follow the thermal load mainly due to solar and internal gains, especially when they are extremely variable during the day. The results of the work show the possibility of reducing the energy demand of the building, and consequently the $\mathrm{CO}_{2}$ emissions, by the use of air handling units as air conditioning systems in residential buildings.
\end{abstract}

Keywords: NZEB, mechanical ventilation, air-handling unit, heat recovery unit.

\section{INTRODUCTION}

Building sector represents about $40 \%$ of the energy consumption and at the same time the $36 \%$ of $\mathrm{CO}_{2}$ emissions in Europe. The 2010 Energy Performance of Buildings Directive (EPBD) [1] and the 2012 Energy Efficiency Directive (EED) [2], are the legislation documents about the improving of the energy efficiency of buildings. The EPDB reports that all new buildings must be Nearly Zero Energy Buildings (NZEBs) by the end of 2020. The increasing trend of renovation, combined with climate changes and the need for energy efficiency, make NZEB as a promising solution for energy saving and sustainability [3]. Many authors investigated the use of several technologies in order to reduce the primary energy consumption and at the same time the greenhouse emissions. Schibuola et al. [4], investigated the use of heat pumps in HVAC plant systems with the objective of obtaining NZEBs buildings. They found that the introduction of the heat pump as substitute to the boiler for space heating and DHW production is able to give a fundamental contribution to achieve the goal of NZEBs. From the environmental point of view, the elimination of local exhausted gas emissions in buildings located in the urban isles is certainly a further progress towards a better environmental quality inside the cities.

The main technical solution for the reduction of the energy demand of a building is to improve the thermal insulation of the building envelope. García Tremps and Mora [5], studied a method to parameterize energetically the building systems most commonly used in construction. Their main result was the identification and quantification of the different agents of building process with objective criteria for selecting building products and building systems more energetically efficient and appropriate for each location and orientation of the building. On the other hand, the second contribution in the energy losses is the infiltration of the air in the building and also the ventilation rate. D'Este et al. [6], investigated different systems for the improvement of the thermal efficiency related to the ventilation rate of the buildings. They studied a direct heat recovery from the exhaust air and an indirect recovery 
by the use of a heat pump and a combined solution of the first two, by the use of dynamic simulations. They concluded that the best solution is the last one, which uses the heat recovery coupled with the heat pump. Nowadays the building envelope, especially in new constructions, is very airtightness and, for this reason, the use of mechanical ventilation units in buildings is mandatory to guarantee the air change rate [7] and the indoor environmental quality. Hence, ventilation air becomes an important source of energy losses for NZEB, but at the same time, the mechanical ventilation system can exploit the possibility of using the external air to improve the energy performance of the building. These latter systems usually have a heat recovery unit able to exchange the heat between the fresh air and the ejection of exhaust air. The thermal efficiency of this heat recovery unit has been being gradually increased over the time and today efficiencies might reach in nominal conditions up to $90 \%$. The present work is not focused on the thermal behavior and the consequent thermal comfort for a specific case study of a high insulation and low energy consumption building, but rather a generic approach to analyze the adequacy of air conditioning systems currently proposed in residential buildings. In detail, the controlled Mechanical Ventilation System (MVS) is one of the basic equipment used in new buildings and especially in NZEB. The MV is generally designed for the minimum flow rates for the air change or for values suggested by the national standards (e.g. in Italy a typical design value is between $0.5 \mathrm{ACH}$ and 0.6 $\mathrm{ACH})$.

It is easy to understand that in a very well insulated building and equipped with high efficiency heat recovery unit, the thermal demand is poorly dependent on external climatic conditions, while the so-called "gains" such as internal loads (people, lights, appliances, etc.) and solar radiation have become the main issues. These latter heat flux inputs are free contributions until they have a positive effect on the energy balance of the building to maintain the desired indoor environmental comfort conditions. On the other hand, when the gains are higher to those needed they become an additional cost and issue.

\section{THE CASE STUDY}

The case study used in this analysis is a room of a residential dwelling in Milan, in North of Italy and the TRY (Test Reference Year) used as reference climate have been downloaded from the database of Energyplus simulation tool [8]. The room is an open-space used as kitchen and living room and it has a useful area of about $45 \mathrm{~m}^{2}$ with a rectangular shape. The external walls have an overall surface of $90 \mathrm{~m}^{2}$ including $9 \mathrm{~m}^{2}$ of windows. The mean value of the U-value of envelope is about $0.25 \mathrm{~W} /\left(\mathrm{m}^{2} \mathrm{~K}\right)$ and this room is representative of a possible application of NZEB for a mild climate.

In the reference case, the fresh air for the ventilation of the room is obtained by the use of a mechanical ventilation system coupled with a double flow heat recovery which has an efficiency of $90 \%$ and a flow rate of $70 \mathrm{~m}^{3} / \mathrm{h}$, corresponding to an air change rate of $0.6 \mathrm{ACH}$.

\section{METHOD}

The energy analysis of the case study has been done by means of simulations of the building. The main objective of this work is not the detailed study of the thermal behaviour of the room but a critical analysis of the energy saving potential of using an air handling unit (AHU) in residential building applications instead of the common MVS commonly used in residential applications. Several boundary conditions have been defined to create the model of the room close to the real in use conditions. In NZEB, the most important contributions in the energy balance are the loads (internal and solar), since the transmission heat losses throughout the envelope are very low and usually the air change is guaranteed by the MVS as in the present 


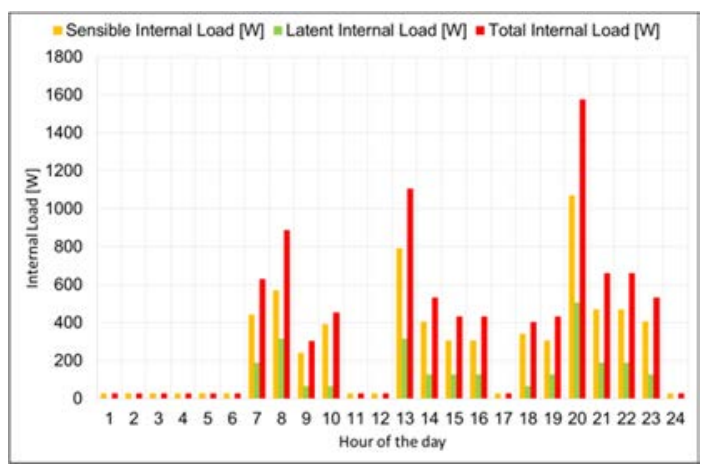

Figure 1: Schedule of the internal loads of the building.

Table 1: Internal load of the buildings.

\begin{tabular}{|c|c|c|c|c|}
\hline Device & $\begin{array}{l}\text { Average } \\
\text { electrical } \\
\text { power }\end{array}$ & $\begin{array}{l}\text { Electrical } \\
\text { power } \\
\text { min/max }\end{array}$ & Use & $\begin{array}{l}\text { Electrical } \\
\text { energy } \\
\text { consumption }\end{array}$ \\
\cline { 2 - 5 }$[\mathrm{W}]$ & {$[\mathrm{W} / \mathrm{W}]$} & {$[-]$} & 355 \\
\hline $\begin{array}{c}\text { Audio-visual } \\
\text { equipment }\end{array}$ & 160 & $100 / 600$ & Daily & 20 \\
\hline Hairdryer & 800 & $600 / 1200$ & $0.5 \mathrm{~h} /$ week & 40 \\
\hline Vacuum cleaner & 1000 & $700 / 2.000$ & $0.75 \mathrm{~h} /$ week & 30 \\
\hline Cooker hood & 150 & $140 / 400$ & $4 \mathrm{~h} /$ week & 100 \\
\hline Iron & 1000 & $1.000 / 2.200$ & $2 \mathrm{~h} /$ week & 100 \\
\hline Electric oveno & 2000 & $1.800 / 2.200$ & $1 \mathrm{~h} /$ week & 296 \\
\hline Fridge (A+) & 200 & $100 / 300$ & Intermittent & 370 \\
\hline Dishwasher & 2100 & $2000 / 2200$ & 5 cycles/week & 225 \\
\hline Washing machine & 2200 & $1850 / 2700$ & 2 cycles/week & 130 \\
\hline PC (desktop) & 200 & $150 / 250$ & Daily & 65 \\
\hline PC (notebook) & 30 & $15 / 40$ & Daily & \\
\hline
\end{tabular}

case study. In this context, an occupancy schedule with the latent and sensible load of the room has been defined as reported in Fig. 1. Common values of sensible internal loads due to appliances are summarized in Table 1, while the latent loads are usually due to people, cleaning and food cooking.

In winter and summer design conditions, the heating and cooling peak loads are $600 \mathrm{~W}$ and $2200 \mathrm{~W}$ respectively. As can be seen in the results of the thermal peak loads, the good thermal insulation of the building envelope involves a significant reduction of transmission and ventilation losses compared to residential stock buildings where the main issue was the heating. During the heating season, the thermal load and consequently the energy demand are low because of the effects of the internal loads and solar gains but during summer the heat fluxes and the correspondent cooling load is about 4 times higher than heating in design conditions.

If peak power cannot be contained, in order to limit energy consumption, a suitable strategy and technical solutions have to be used to limit the operating time of the refrigeration 
system, such as free-cooling operation. All this is even more important if one considers that refrigeration mostly implies the use of electricity and that the main objective of the modern design is to obtain a NZEB building.

Different operating conditions and air ventilation systems have been investigated, in particular the room uses different systems for the ventilation, heating and cooling. The work is not focussed on the type of emission system but rather on the effect of using air system in order to exploit as much as possible the free-cooling operation. The following cases have been compared:

- a common MVS without the bypass of the heat recovery unit has been considered as basic case;

- a more complicated complete case consists of an AHU for the air-conditioning and the fresh air change of the room.

This last hypothesis is not common nowadays in residential buildings despite the great potential in energy saving. In all the case studies, the emission systems have been considered as ideal because the effect of the behaviour of different types of emission systems is not the aim of the work.

\section{ENERGY ANALISYS}

\subsection{System with mechanical ventilation unit}

In the first part of this work, the energy analysis has been carried out considering the solar gains in the heat balance of the room without the internal loads. The energy balance of the room for two days in winter period are shown in Fig. 2 and Fig. 3 for different values of the external mean temperature $\left(2.6^{\circ} \mathrm{C}\right.$ and $8.3^{\circ} \mathrm{C}$ as average outdoor temperature respectively). As can be seen in the charts, the energy balance of the room without internal loads always needs heating during the day with low external temperature. A small amount of cooling should be provided from 3 p.m. to 10 p.m. in the warmest day in order to maintain the indoor temperature fixed at design conditions $\left(20^{\circ} \mathrm{C}\right)$.

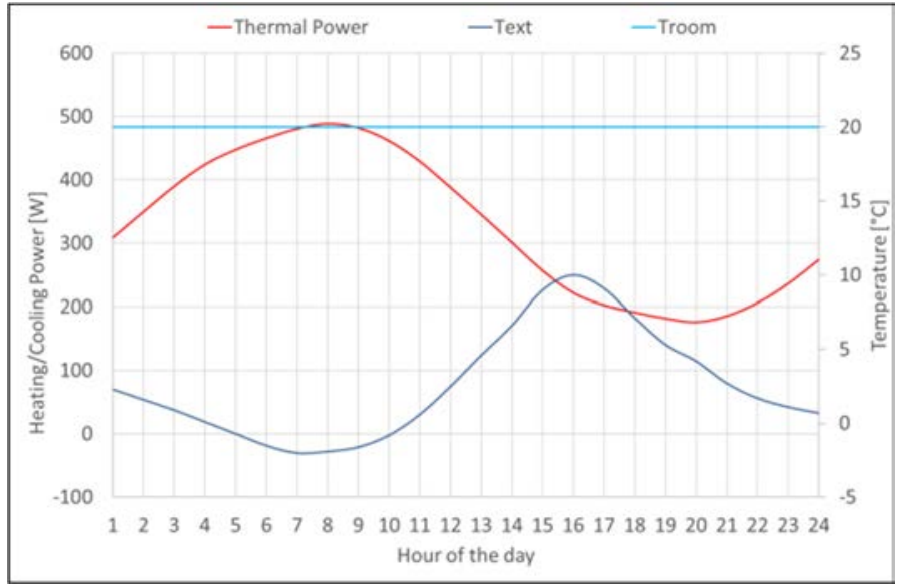

Figure 2: Thermal behaviour of the room for one day during the heating period with external mean temperature of $2.6^{\circ} \mathrm{C}$ without internal loads. 


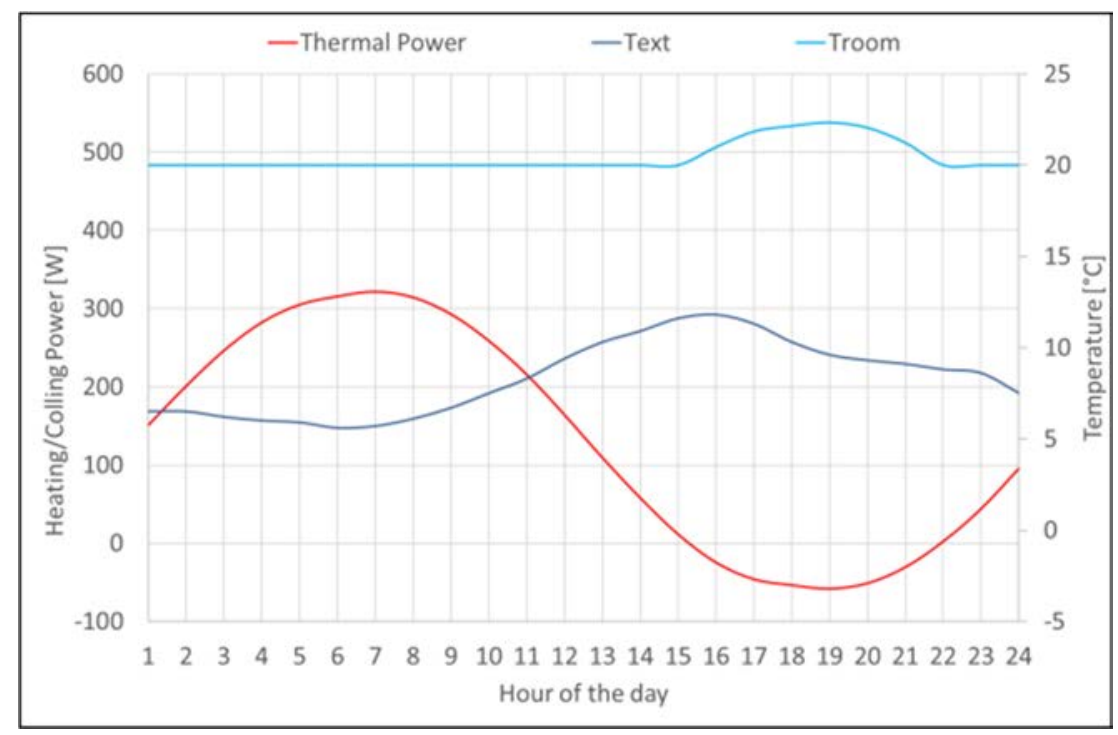

Figure 3: Thermal behaviour of the room for one day during the heating period with external mean temperature of $8.3^{\circ} \mathrm{C}$ without internal loads.

The second analysis has been carried out using the case above described, with the same boundary conditions, adding the contributions of the internal loads. As can be expected, considering the internal loads defined in Fig. 1 implies worse comfort conditions. The charts in Figure 4 and Figure 5 show the trend of the thermal load and indoor temperature considering the heat gains including the internal loads.

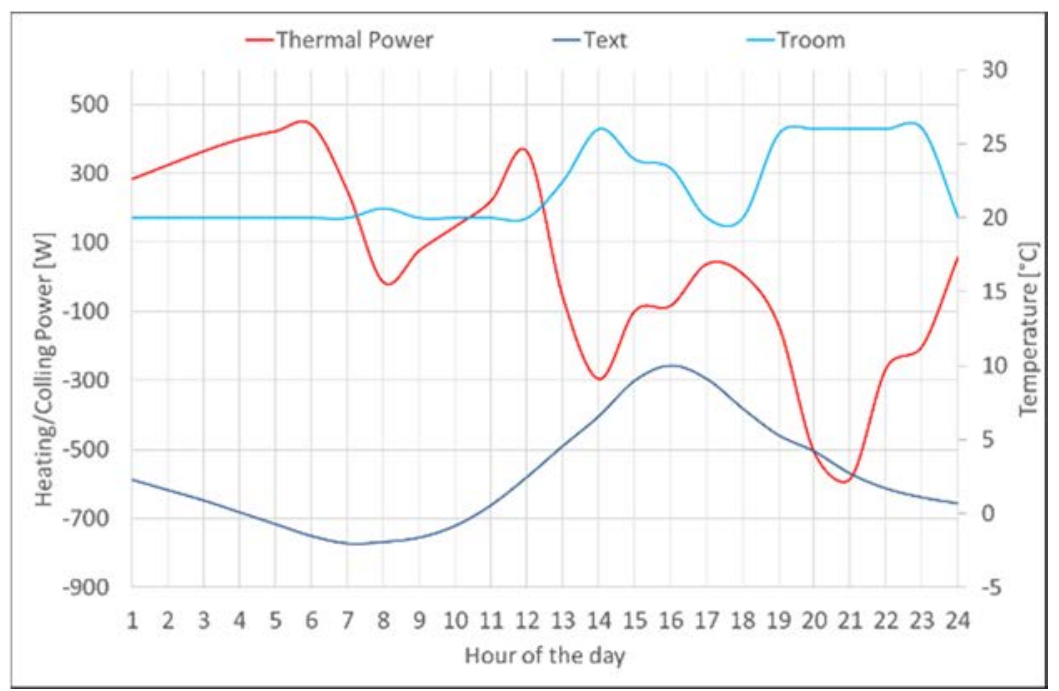

Figure 4: Thermal behaviour of the room for one day during the heating period with external mean temperature of $2.6^{\circ} \mathrm{C}$ considering internal loads. 


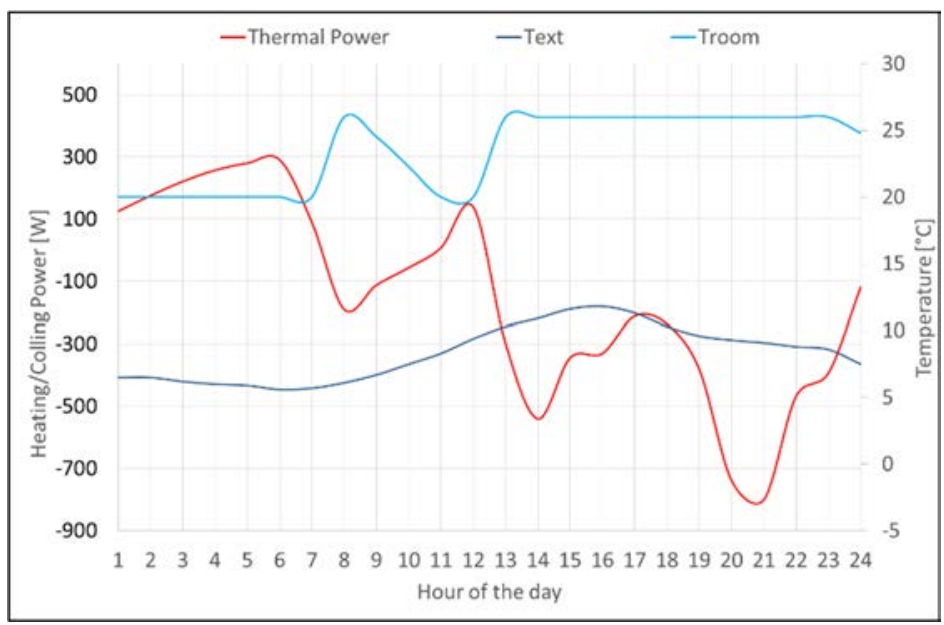

Figure 5: Thermal behaviour of the room for one day during the heating period with external mean temperature of $8.3^{\circ} \mathrm{C}$ considering internal loads.

As can be seen, the internal loads rate and the lack of the bypass of the heat recovery imply an increase of the cooling demand of the room even in winter period, where the room temperature becomes close to values typical of the summer period. The only solution for this configuration of the plant system would consist in the manual opening of the windows by the users. On the other hand, especially in urban areas, as effect of this action not filtered external air with contaminants would enter in the room. Noise would also enter into the room when opening the window. The low outdoor temperatures would suggest of cooling the room directly with the outside air through the bypass of the heat recovery.

Examining the operation of a system equipped with a bypass on the heat recovery, promising results can be obtained from the energy point of view. The use of cold air directly from the outdoor ambient is the so-called free-cooling method. In cold season, it has no sense to use the cooling by the air conditioning systems but it results more efficient the direct use of the external cold air.

The cooling rate obtained from the external air to the room can be calculated with the eqn (1), where $G$ is the mass flow rate, $c_{p}$ is the heat capacity of the air, $T_{\text {room }}$ and $T_{\text {ext }}$ are the room and the external temperature respectively:

$$
\mathrm{Q}_{\mathrm{FC}}=\mathrm{G} * \mathrm{c}_{\mathrm{p}} *\left(\mathrm{~T}_{\mathrm{ext}}-\mathrm{T}_{\text {room }}\right) \text {. }
$$

Usually the mass flow rate of the residential systems is constant and therefore the cooling rate is a function of the external temperature. The free-cooling could certainly improve the thermal comfort and at the same time could reduce the energy consumption for cooling. However, some considerations need to be made.

The mechanical ventilation unit of a residential building is generally centralized; the fresh air is supplied into the rooms under the same conditions and with a specific flow rate. Moreover, when the bypass of the heat recovery is present, free-cooling is managed by means of a motorized damper that operates with on/off logic. There might be moments when living room may require free-cooling and night zone may require heating. In these circumstances, a central decision will undercool some zones. 
As already shown, even when outside temperature is below $5^{\circ} \mathrm{C}$ there might be a need for cooling. The use of the by-pass of the heat recovery unit means to supply air at outside temperature and this could lead to discomfort (like opening the windows). Moreover, there might be other rooms that need heating at the same time. While agreeing to supply air at low temperatures in the living space, it would be necessary to heat the night zone with postheating coils. This solution is no longer able to benefit from the preheating effect produced by the heat recovery unit, hence a significant increase in energy consumption for heating could be a consequence, thus obtaining the opposite result to that desired. In Fig. 6 the chart of these operating conditions is reported.

The chart shows the heating load demand, the cooling load that would be provided by the free-cooling and the additional heating load required for supplying air to other rooms. This last thermal load rate has been calculated considering a flow rate of $70 \mathrm{~m}^{3} / \mathrm{h}$ that needs to be heated from the $T_{\text {ext }}$ to the $T_{\text {room. }}$. It should be noted that although external temperatures are low, free-cooling cannot fully meet the cooling demand. In the day used as an example in the present study, its contribution is about $3 \mathrm{kWh}$ while there is still a cooling demand of $4 \mathrm{kWh}$, which leads to an incidence of $43 \%$. When the bypass is used, as mentioned above, it is necessary an additional load to heat the air for the other rooms in the night zone for example. The energy demand amounts to $5.7 \mathrm{kWh}$ which are added to the energy required for normal heating and is equal to $1.6 \mathrm{kWh}$, an increase of $456 \%$.

As a result, in these conditions, in spite of saving $3 \mathrm{kWh}$ of cooling, $5.7 \mathrm{kWh}$ would be spent in heating. A better solution would be to make possible to use the by-pass only when the outside temperature is at least $16^{\circ} \mathrm{C}$.

In this case, the possibility of free-cooling is limited to midseason and summer periods when $\mathrm{T}_{\text {ext }}$ is between $16^{\circ} \mathrm{C}$ and the set-point temperature of the rooms.

This means that current centralized mechanical ventilation systems present in the market are not suitable to solve the issue of excessive heating that is already occurring during the winter season in NZEB in mild climates.

A similar energy analysis has been carried out for a day with an external mean temperature equal to $26.8^{\circ} \mathrm{C}$ during the cooling period. The chart in Fig. 7 shows the results of this simulation.

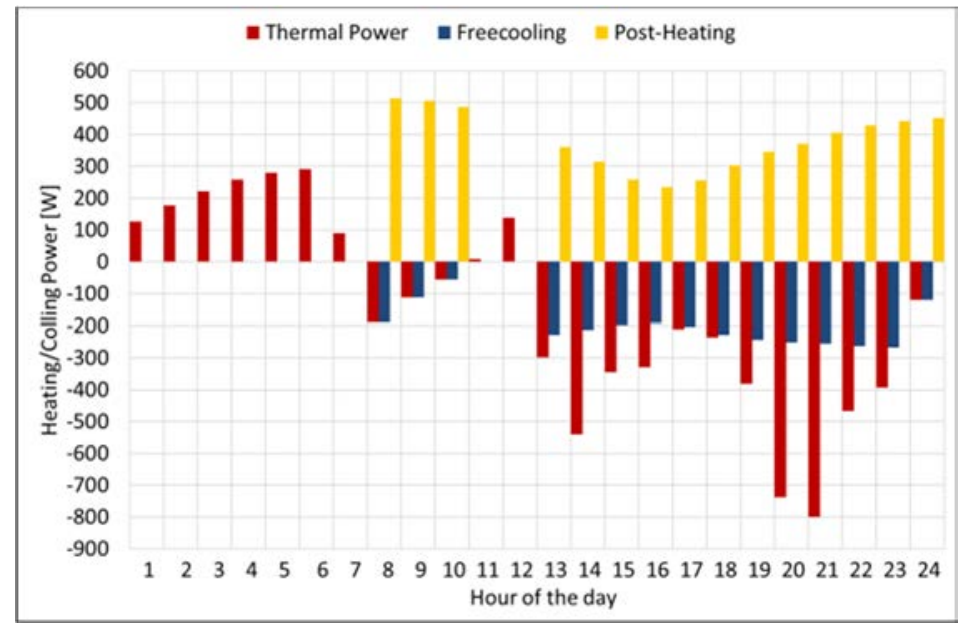

Figure 6: Effect of the use of bypass for the heat recovery unit. 


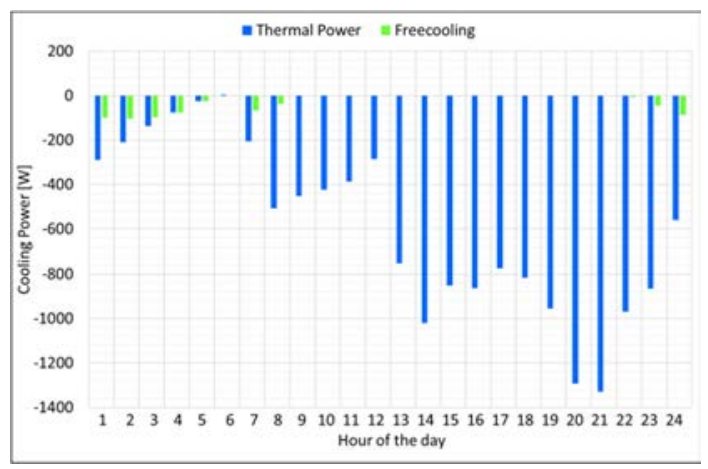

Figure 7: Effect of the use of the bypass to the heat recovery unit

As it can be seen, the magnitude of the free-cooling contribution is not so high, being strongly limited by the small temperature differences between the external and room temperature and the low air flow rate.

The energy analysis has been extended to the whole year in order to estimate the contribution of the free-cooling operation during the two main seasons, winter and summer. The yearly simulation results are summarized in Table 2 .

As it can be seen the energy need reduction appears to be modest (about 5\%) and the potential energy saving offered by free-cooling seems to have been frustrated. With this type of plant, the only possibility of cooling the environment seems to be to open the windows or activate the refrigeration plant.

A system like the one above described, despite the consequent energy consumption, is not usually implemented with the most commonly residential air conditioning systems, for example systems which use radiant panels as emission units. For this type of system, it is not conceivable to switch over during the day the operating mode from heating to cooling and vice versa.

Under these conditions, it is possible to obtain the most benefit from the use of local MVS consisting of independent devices installed in each room. While maintaining the low input temperature and low flow rate limits, the local system allows to use the free-cooling during the winter season only where it is necessary. Removing the temperature constraint and the need to heat the supply air in the other environments it is possible to evaluate which the achievable benefit can be in terms of energy saving.

Table 2: Energy needs for heating and cooling for the system with and without the heat recovery bypass.

\begin{tabular}{|c|c|c|}
\hline Thermal Energy & $\begin{array}{c}\text { Without } \\
\text { by-pass }\end{array}$ & $\begin{array}{c}\text { With } \\
\text { by-pass } \\
\left(\text { Text }>16^{\circ} \mathrm{C}\right)\end{array}$ \\
\cline { 2 - 3 } & {$[\mathrm{kWh}]$} & {$[\mathrm{kWh}]$} \\
\hline Heating & 580 & 580 \\
\hline Free-cooling & 0 & 158 \\
\hline Cooling & 3411 & 3242 \\
\hline
\end{tabular}


Table 3: Energy needs for heating and cooling for the system with local mechanical ventilation.

\begin{tabular}{|c|c|}
\hline Thermal Energy & $\begin{array}{c}\text { Local } \\
\text { Mechanical } \\
\text { Ventilation }\end{array}$ \\
\cline { 2 - 2 }$[\mathrm{kWh}]$ \\
\hline Heating & 680 \\
\hline Free-cooling & 563 \\
\hline Cooling & 2433 \\
\hline
\end{tabular}

In this case, it should be noted that the recovery efficiency of the punctual devices is on average less than $90 \%$ and here is assumed equal to $80 \%$. The results of the simulation of this approach are summarized in Table 3.

As can be seen, the results show an increase of $18 \%$ of the energy required for heating and a reduction of $29 \%$ in the energy required for cooling with respect to a common MVS without by-pass.

\subsection{System with air handling unit}

In a NZEB, the MVS must be perfectly integrated with the air conditioning system. Usually the latter is made up of radiant panels (floor, ceiling, etc.) coupled with a dehumidification system that may be matched to the MVS.

As it has been already described, during the day, the thermal requirement can move from heating to cooling and vice versa in a short time. The main objective, in order to maximize the energy saving potential, is to use free-cooling properly and as long as possible.

A system with an AHU can incorporate all the required functions for fresh air exchange, heat recovery, heating, cooling, dehumidification and last but not least a free-cooling with a much higher capacity than common mechanical ventilation systems. This system can quickly respond to thermal load fluctuations of the building during the day, due to reduced thermal heat capacity of the air.

An energy simulation of an AHU designed to provide the minimum air change flow rate through the heat recovery unit has been carried out; the unit has the possibility to work either with a recirculation or to work with external fresh air only. The functional diagram of the AHU used in the simulation is shown in Fig. 8.

The Return Fan (RF) in Fig. 8 provides to collect the air from the rooms after the filter (FL). The air flow recovered by the RF is then ejected and recirculated. The ratio between the ejected flow rate and recycled air flow rate, if heat recovery is useful, is modified by means of a damper inserted into the renewal air supply unit and the damper $\mathrm{D}$ in such a way as to ensure that the minimum required air change.

A similar system has been simulated for the air conditioning of the case study used in the previous analysis. The system has a maximum flow rate of $500 \mathrm{~m}^{3} / \mathrm{h}$ while the minimum delivery temperature is $14^{\circ} \mathrm{C}$. This latter value allows an adequate dehumidification during cooling operation and at the same time this temperature can always be assured, even in winter conditions, by the outdoor recirculation air mixture. 


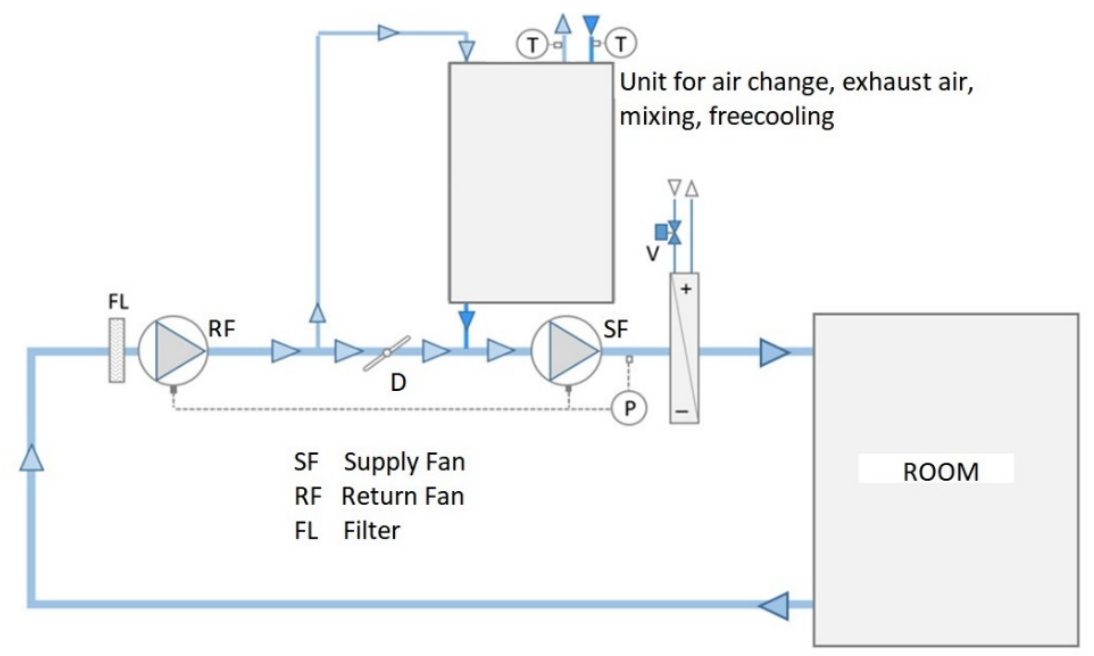

Figure 8: Functional diagram of the air handling unit.

In Fig. 9 and Fig. 10 the results of the simulations for the heating and cooling days are summarized. In the day of the heating period (Fig. 9) it can be seen how the AHU is able to meet the needs of cooling using the free-cooling mode without the use of cooling coils. In cooling period, as shown in Fig. 10, the effect of free-cooling is less effective but still significant because of the reduced difference of temperature between the external and the room temperatures. On the other hand, the yearly energy results well demonstrate the energy saving potential of this plant solution as reported in Table 4.

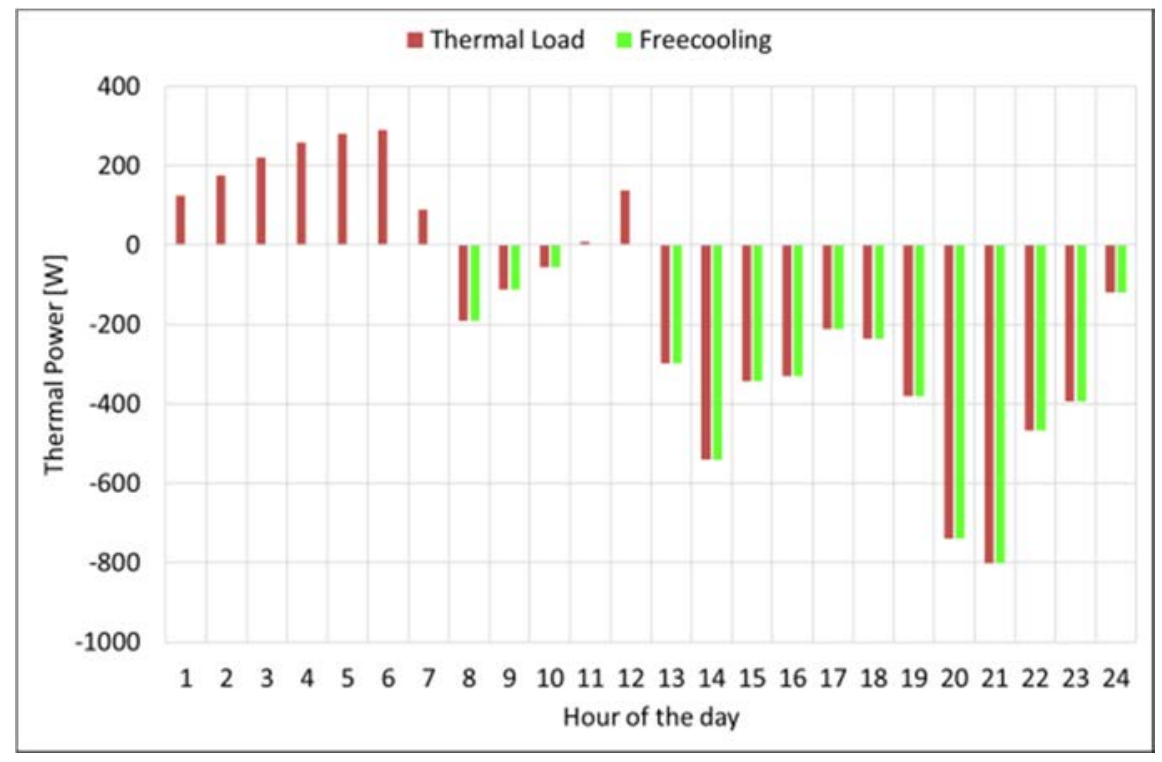

Figure 9: Effect of the use of air handling unit in the case of heating season, daily mean temperature $8.3^{\circ} \mathrm{C}$. 


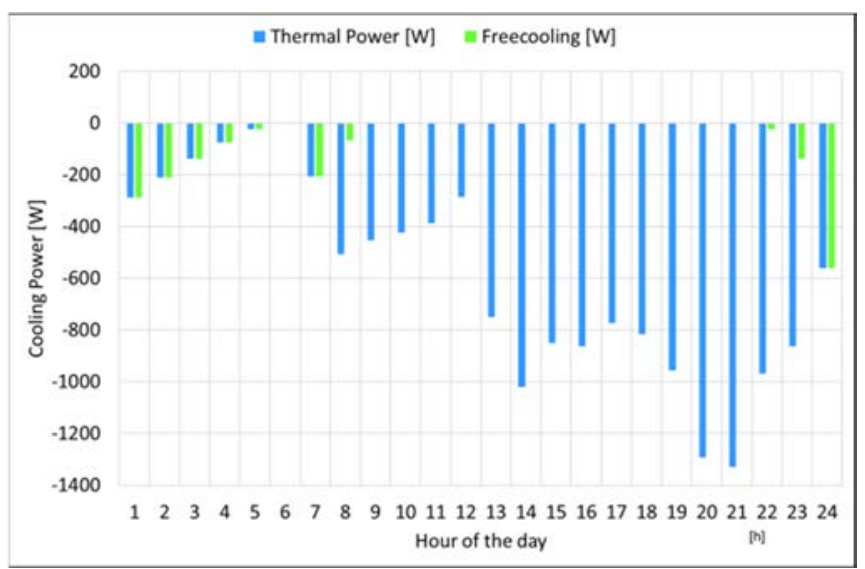

Figure 10: Effect of the use of air handling unit in the case of cooling season, daily mean temperature $26.8^{\circ} \mathrm{C}$.

Table 4: Energy needs for heating and cooling for the air handling unit.

\begin{tabular}{|c|c|}
\hline Thermal Energy & $\begin{array}{c}\text { Air handling } \\
\text { unit }\end{array}$ \\
\cline { 2 - 2 } & {$[\mathrm{kWh}]$} \\
\hline Heating & 580 \\
\hline Free-cooling & 1366 \\
\hline Cooling & 1482 \\
\hline
\end{tabular}

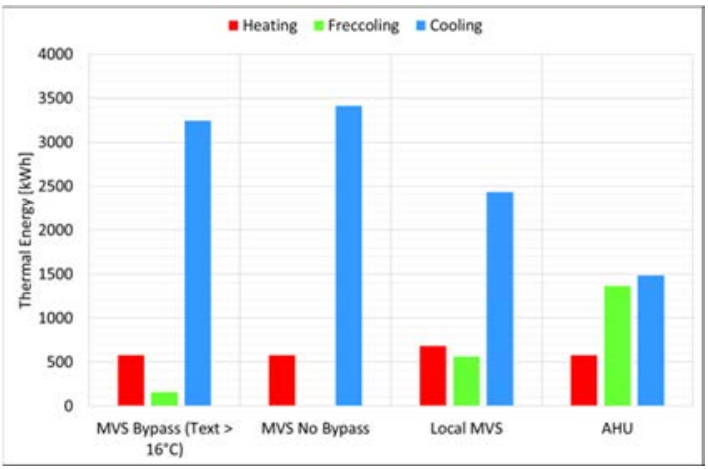

Figure 11: Comparison of the results of the simulations for the case study(MVS: mechanical ventilation system, AHU: air handling unit).

In Fig. 11 the comparison of the results of the simulations for the investigated systems has been summarized. The free-cooling with the AHU solution can cover the demand for cooling by almost $50 \%$. It saves about $57 \%$ of the energy used for cooling compared to a common 
mechanical ventilation system without bypass, and about $39 \%$ if compared with the local one that had given best performance.

\section{CONCLUSION}

The NZEBs will be the standard technology for new construction in the building sector. The mechanical ventilation systems or natural ventilation equipment are already necessary for indoor air quality issue. The MVS coupled with a water based system could be not always the best solution for providing heating/cooling demand in NZEBs.

Reduced free-cooling capabilities may require the use of the cooling system for long time period and consequently the increase of energy consumption.

The optimum solution could consist in providing a full-fledged system, like a small airhandling unit, to perform all the functions of air conditioning, air renewal, heat recovery, dehumidification and free-cooling for each room served.

\section{REFERENCES}

[1] Directive 2010/31/EU of the european parliament and of the council of 19 May 2010 on the energy performance of buildings (recast).

[2] Directive 2012/27/EU of the european parliament and of the council of 25 October 2012 on energy efficiency, amending Directives 2009/125/EC and 2010/30/EU and repealing Directives 2004/8/EC and 2006/32/EC.

[3] Charisi, S., The Role of the Building Envelope in Achieving Nearly-Zero Energy Buildings (nZEBs). Procedia Environmental Sciences 38, pp. 115-120, 2017.

[4] Schibuola, L., Martini S., Scarpa M. \& Tambani C., Towards near zero energy dwellings by heat pump implementation in HVAC plants. WIT Transactions on Ecology and The Environment, 165 pp. 289-298, 2012.

[5] García Tremps, A. \& Mora, D., Energy performance assessment of building systems with computer dynamic simulation and monitoring in a laboratory, WIT Transactions on Ecology and the Environment, 143, pp. 449-460, 2011.

[6] D'Este, A., Gastaldello, A. \& Schibuola, L., Energy saving in building ventilation, WIT Transactions on Ecology and the Environment, 81, pp. 335-344, 2005.

[7] Guillén-Lambeaa, S., Rodríguez-Soria, B. \& Marín, J.M., Control strategies for Energy Recovery Ventilators in the South of Europe for residential nZEB - Quantitative analysis of the air conditioning demand. Energy and Buildings 146, pp. 271-282, 2017.

[8] EnergyPlus Simulation Tool - Weather data, https://energyplus.net/weather. Accessed on: 22 May 2017. 